\title{
Spatial and Temporal Variations of Precipitation in and around Bangladesh
}

\author{
Md. Nazrul ISLAM \\ Department of Physics, Bangladesh University of Engineering \& Technology, Dhaka, Bangladesh \\ Toru TERAO \\ Faculty of Informatics, Osaka Gakuin University, Suita, Japan
}

Hiroshi UYEDA

Hydrospheric Atmospheric Research Center, Nagoya University, Nagoya, Japan

Taiichi HAYASHI

Disaster Prevention Research Institute, Kyoto University, Kyoto, Japan

and

Katsuhiro KIKUCHI

Department of Biological Environment, Akita Prefectural University, Akita, Japan

(Manuscript received 6 February 2003, in final form 9 September 2004)

\begin{abstract}
Radar data from the Bangladesh Meteorological Department (BMD) are employed as a preliminary analysis. This is a first research work to investigate the spatial and temporal distribution of rainfall over the country for 135 consecutive days, from 16 April to 30 August 2000. Radar data are sampled in $10 \mathrm{~km}$ grid boxes to obtain daily rainfall over the country. Rain gauge data at 33 locations are utilized to check the radar results. The distributions of rainfall obtained by both the radar and the rain gauges are similar in pattern, but the time of the maximum rainfall determined by the radar is a few hours earlier than that determined by the rain gauges. The distribution of rainfall over the whole radar domain suggests that 21 to 09 local standard time (LST) is the most likely time for rainfall to occur in Bangladesh, while 06 LST is the most likely time for maximum rainfall to occur over the entire country. It is mentioned that no data are available between 03-06 LST. The occurrence of 21 to 09 LST rainfall is possibly linked to the local effects such as complex terrain and sea and land breeze circulations. The morning maximum rainfall at 06 LST in Bangladesh is different from that of the Indian subcontinent or of the mountain area where, generally, maximum rainfall occurs in the afternoon. The northern border of Bangladesh, close to the Shillong hill of India, is the region with the highest rainfall, while the second highest volume
\end{abstract}

Corresponding author: Md. Nazrul Islam, Department of Physics, Bangladesh University of Engineering \& Technology, Dhaka-1000, Bangladesh. E-mail: mnislam@phy.buet.ac.bd

(C) 2005, Meteorological Society of Japan 
of rainfall occurs on the eastern border. In order to observe the characteristics of large-scale cloud activity, analyses of the Japanese GMS-5 hourly infrared data, within a larger domain of $80-100^{\circ} \mathrm{E}$ and $10-$ $30^{\circ} \mathrm{N}$ were conducted. The cloud activities in and around Bangladesh were obtained in $1^{\circ}$ by $1^{\circ}$ grid boxes. The northwestern part of Bangladesh was largely affected by pre-monsoon clouds, while the whole country was affected by the peak monsoon activities.

\section{Introduction}

South Asia is well known in the world as a summer monsoon region, and Bangladesh is a heavy rainfall area in it. Geographically, Bangladesh is a narrow flat lowland, the Bay of Bengal is located in the south, and the highly elevated Himalayas and Tibetan Plateau are situated in the north. These geographical features are very favorable for development of convection, because the water vapor transported by the monsoon winds from the Bay of Bengal and highly elevated regions cause development of convection in Bangladesh.

It is well known that two-thirds of the world's rain falls in the tropics, and rainfall is related to the amount of latent heat transported from the surface to the atmosphere. Large volumes of rain indicate a considerable amount of heating of the atmosphere in that region, and this is the energy source for global atmospheric circulation. In fact, the largest value of both apparent heat source and moisture sink in the South Asian region was found over Bangladesh during summer monsoon season in 1979 (Luo and Yanai 1984). Therefore, it is important to determine the precise distribution of rainfall in South Asia that contributes significantly to the tropical rainfall in order to understand the water cycle as well as the global circulation of the atmosphere. Furthermore, precipitation is one of the most difficult atmospheric parameters to measure because of the large variations in space and time (Kummerow et al. 2000). In addition, proper knowledge of the spatial and temporal variations of precipitation is essential for the agricultural sector in that region.

A radar facility was installed at the headquarter of the Bangladesh Meteorological Department (BMD) in 2000, but unfortunately, no research was carried out on the distribution of rainfall over Bangladesh using this radar data so far. The BMD uses the radar data for operational real time forecasting and dose not archive the data for research purposes. Then, only the rain gauges data have been used for these purposes. However, the low-density rain gauge network over Bangladesh is insufficient to have a precise record of the precipitation distribution over the country. The rain gauge stations on the northern side of Bangladesh are few, and there is no rain gauge station on the north side of the Bay of Bengal and offshore. Therefore, we made an attempt to employ the radar data for obtaining precipitation distribution over Bangladesh.

The Tropical Rainfall Measuring Mission (TRMM), which has been highly successful in measuring rainfall from space, was launched on 27 November 1997. Kummerow et al. (2000) have summarized the goals of TRMM, its products, and sensors synergy. The TRMM passes infrequently over Bangladesh only once a day. There has been no ground-based validation performed over Bangladesh with TRMM data yet. Hence, continuous measurements are needed to understand the temporal and spatial variations of precipitation in that region. To fulfill this, we analyzed the data of the groundbased radar that can detect precipitation areas and amounts very frequently. Thus, we archived the radar observation data of the BMD by ourselves. For the first time, comprehensive studies using weather radar data along with conventional rain gauge were carried out. Japanese GMS data were also used for understanding the cloud activity during the premonsoon to monsoon period in and around Bangladesh.

The patterns and strength of rainfall, and the time and location of maximum falling in different spatial and temporal scales vary from the average value obtained from the peak monsoon months. For example, Ohsawa et al. (2001, Fig. 1) reported that the hourly-mean rainfall in JJA of 1995 shows a primary peak at 04 LST and a secondary peak at 19 LST at a northeastern rain gauge station $\left(24.92^{\circ} \mathrm{N}, 91.83^{\circ} \mathrm{E}\right)$ of Bangladesh. This station is not a regular rain gauge station of the $\mathrm{BMD}$, but it is one of the 9 


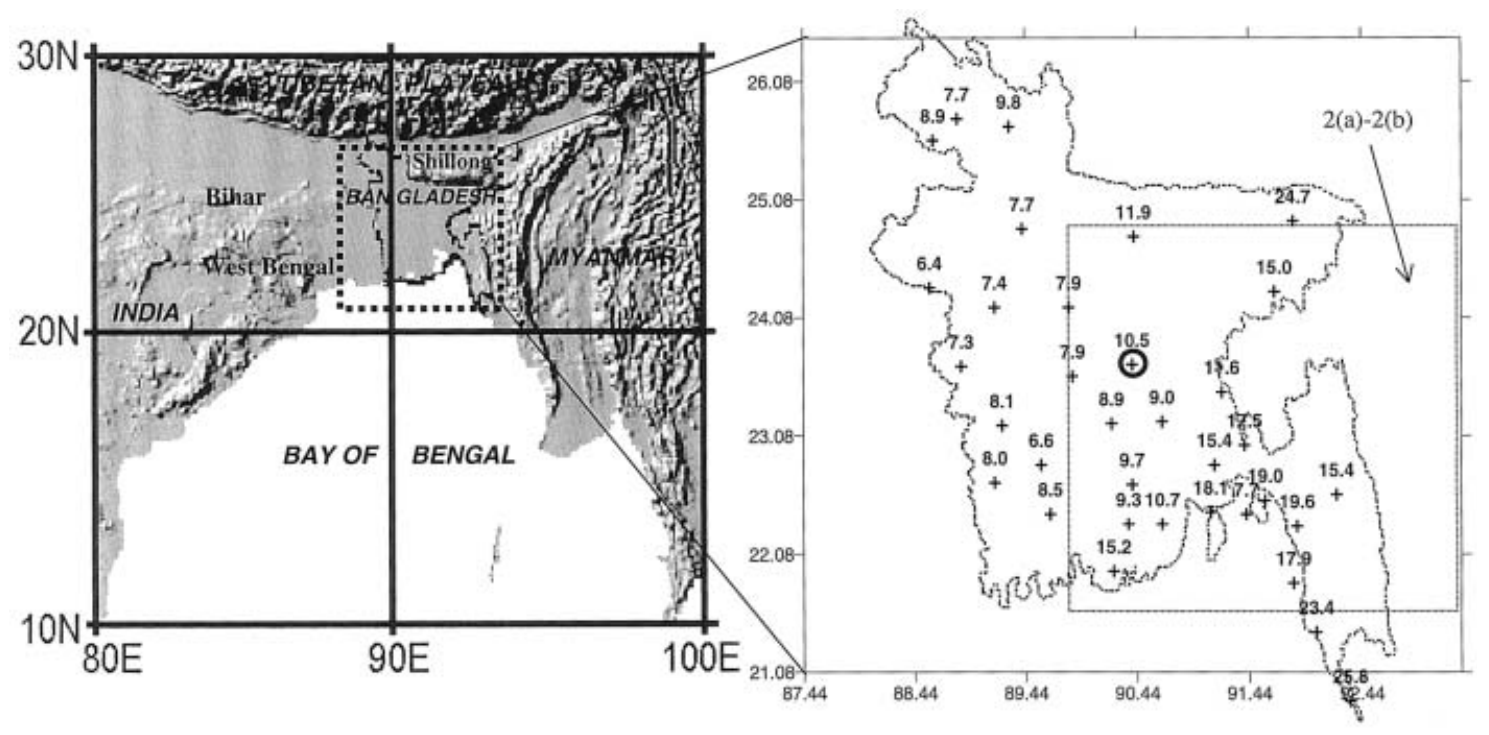

Fig. 1. Analysis area with topographic shades (left panel). The dashed bold rectangle in the left panel represents the coverage of the Dhaka radar. The right panel represents monthly averaged daily rainfall $(\mathrm{mm})$ for July 2000 determined by rain gauge. The circle at the center of Bangladesh indicates the radar site. The plus mark represents the location of the BMD rain gauge stations over Bangladesh. The dashed rectangle in the right panel is used for Figs. 2(a) and 2(b).

stations installed under a Japan International Cooperation Agency (JICA) project (Islam et al. 2001). Wahid and Islam (1999) examined the patterns of rainfall using hourly data from JICA's 9 rain gauges during the monsoon season of 1995-1996. Out of the 9 stations, 5 showed a morning (04-05 LST) peak, 2 showed an afternoon (16-19 LST) peak, and the remaining 2 showed a noon (12-14 LST) peak. Matsumoto (1988) and Matsumoto et al. (1996) discussed the flood situation in Bangladesh and pointed out that heavy rainfall in that region is one of the causes of flooding. They also sought the reason of flood in excessive rainfall over large catchment areas of the Ganges, Brahmaputra, and Meghna (GBM) rivers as well as excessively high sea levels associated with the Indian Ocean Zonal Mode. Karmaker and Khatun (1995) studied the probabilistic estimates of rainfall during a southwest monsoon using monthly mean rain gauge data and reported a spatial variation of rainfall over Bangladesh. Therefore, a detailed examination using high spatial and temporal resolutions data is needed to identify the phenomena occurring there.

The Global Energy and Water Cycle Ex- periment (GEWEX) is a major subprogram of the World Climate Research Program (WCRP), and the GEWEX Asian Monsoon Experiment (GAME) was initiated to understand the energy and water cycle process in the Asian monsoon region and its impact on global climate change. Earlier studies (MONSOON-77, MONEX-79) have suggested that atmospheric conditions over the Bay of Bengal differ from that of the equatorial western Pacific warm pool during the Tropical Ocean Global Atmosphere Coupled Ocean-Atmosphere Response Experiment (TOGA-COARE) (Webster and Lukas 1992). The precipitable cloud portion in and around Bangladesh is about $74 \%$ (Wahid et al. 1999), which differs from the equatorial western Pacific warm pool, i.e., 56\% during the TOGA-COARE intensive observational period (IOP) (Islam et al. 1998). Over the Bay of Bengal, the winds are much stronger during the monsoon, often greater than $8 \mathrm{~ms}^{-1}$, whereas, over the west Pacific, they are light, only occasionally exceeding $4 \mathrm{~ms}^{-1}$ (Weller and Anderson 1996). The first observational experiment under the Indian Climate Research Programme (ICRP), called the Bay of Bengal Monsoon Ex- 
periment (BOBMEX), was carried out during July-August 1999 (Bhat et al. 2001). BOBMEX aimed to measure important variables of the atmosphere, the ocean, and their interface and to gain deeper insights into the processes that govern the variability of organized convection over the Bay of Bengal and to study its impact on climate change. However, GAME IOP and BOBMEX observational data did not include Bangladesh.

The data of the BMD radar provided good spatial and temporal resolution of the precipitation in Bangladesh. In addition, GMS-5 data in a domain of $80-100^{\circ} \mathrm{E}$ and $10-30^{\circ} \mathrm{N}$ were used to examine clouds in and around Bangladesh.

\section{Data and method of analysis}

The data utilized in this work include the rainfall amount from the rain gauges, Plain Position Indicator (PPI) scans of the radar, and infrared channel-1 (IR1) images of GMS-5. The Bangladesh Meteorological Department (BMD) collects rain gauge rainfall at 3 -hour intervals at 33 ground stations (plus mark in Fig. 1) over the country. The BMD installed an S-band weather radar (wavelength: $\sim 10 \mathrm{~cm}$ ) at Dhaka $\left(90.4^{\circ} \mathrm{N}, 23.7^{\circ} \mathrm{E}\right)$ on the roof of a building with height $60 \mathrm{~m}$ (circle mark in Fig. 1), which provides a coverage of $600 \mathrm{~km}$ by $600 \mathrm{~km}$ rectangular area. The altitude of radar site is $8 \mathrm{~m}$ above sea level. Hereafter, this radar is called Dhaka radar. The maximum radius of the Dhaka radar is firstly designed as $400 \mathrm{~km}$, but, at present, its effective radius is about $250 \mathrm{~km}$. It is operated at a frequency of 2700$2900 \mathrm{MHz}$, with a beam width of $1.7^{\circ}$. The Dhaka radar is operated with only zero elevation angles and collects PPI scan data (pixel size: $2.5 \mathrm{~km}$ mesh) at 2-3-minute intervals continuously for 1 hour with a 2-hour break during operation. It is noted that there is no high building around the radar site. The radar stops operation at 03 LST everyday. We, for the first time, archived the Dhaka radar data by ourselves from 16 April to 30 August 2000.

The Dhaka radar collects reflectivity data. They are automatically converted into rain statuses and stored in six categories, which are referred as status 1 , status 2 , status 3 , status 4 , status 5, and status 6. Rain rates are retrieved from rain statuses as discussed here. This retrieval result is used to estimate real-time rainfall (Anagnostou and Karajewski 1999). The space-time averaged rain rate is estimated as follows. Radar data are averaged in $10 \mathrm{~km}$ grid boxes; each grid contains 16 pixels, and each pixel is a $2.5 \mathrm{~km}$ mesh.

The instantaneous rain rate $R_{I}$ is defined as

$$
R_{I}=\left(1 / A_{R}\right) \sum_{r=1}^{r=6} S_{r} A_{R, r}
$$

where $r$ is the rain status, $S_{r}$ is possible rainrate correspond to each status and $A_{R}$ is the rainy area of each rain status in a $10 \mathrm{~km}$ grid box. In this analysis, we use $S_{r}$ values as $2.5,10.5,24.5,48.5,96.5$, and $129 \mathrm{~mm} / \mathrm{h}$ for $r=1,2,3,4,5$, and 6 , respectively.

The spell rain rate $R_{S}$ is defined as

$$
R_{S}=(1 / N) \sum_{I=1}^{I=N} R_{I}
$$

where $R_{I}$ is the instantaneous rain rate in a $10 \mathrm{~km}$ grid box calculated from Eq. (1) and $N$ is the total number of PPI scans during the spell duration.

The hourly rain rate $R_{H}$ is defined as

$$
R_{H}=(1 / N) \sum_{t=1}^{t=N} R_{t}
$$

where $N$ is the total number of scans in an hour and $R_{t}$ is the instantaneous rain rate of a $10 \mathrm{~km}$ grid box per unit area instead of rainy area with

$$
R_{t}=\left(1 / A_{G}\right) \sum_{r=1}^{r=6} S_{r} A_{R, r},
$$

where $A_{G}$ is the grid area, which is $100 \mathrm{~km}^{2}$ in this analysis. Daily and monthly rainfalls were then calculated from hourly rain rates.

Hourly equivalent Black Body Temperature $\left(T_{B B}\right)$ data of GMS-5 IR1 are processed for the $10 \mathrm{~km}$ mesh in a domain of $80-100^{\circ} \mathrm{E}, 10-30^{\circ} \mathrm{N}$ from April to September 2000 in order to see the large-scale cloud activity and to compare with the radar observations. Spectral analysis is performed on the hourly $T_{B B}$ data to obtain the cloud activity in the analysis region. $T_{B B}$ data are averaged in a $1^{\circ} \times 1^{\circ}$ grid from 100 pixels with a size of $0.1^{\circ}$ mesh. The cloud area 
is defined as the area where $T_{B B}$ is below the threshold temperature of $263 \mathrm{~K}$. The regions above the threshold temperature are defined as clear sky. The time of maximum activity is obtained when the minimum $T_{B B}$ area becomes the largest.

\section{Results}

\subsection{Instantaneous and spell rain rate}

The instantaneous and spell rain rates, excluding rainless grids $(\mathrm{mm} / \mathrm{h})$, are calculated using Eqs. (1) and (2), respectively. Examples of instantaneous (1715 LST) and spell (17021759 LST) rain rate on 26 May 2000 are shown in Figs. 2(a) and 2(b). The area of those figures is a dashed rectangle in the right panel of Fig. 1 . The spell rain rate is lower than the instantaneous rain rate. The precipitation system in Fig. 2(b) comprises a single continuous rain area, in which relatively intense precipitation cores are interconnected with lighter precipitation area. This precipitation pattern is similar to that in the mid-latitudes (Houze 1993). Detail characteristics of precipitation such as lifetime, size, propagation speed and direction, and development location will be described in a separate paper.

\subsection{Hourly and daily rainfall}

Figure 3 represents an example of distributions of hourly and daily rainfall $(\mathrm{mm})$ calculated from Eq. (3) on 25 April 2000. On this day, the BMD reported $9.6 \mathrm{~mm}$ rainfall averaged over the country. Surface wind blew easterly in the north and southwesterly to the south of the country. Low temperature and pressure persisted to the north and high temperature and pressure to the south. Cloud coverages were high percentage $(\sim 80 \%)$ in the west and low $(\sim 10 \%)$ in the south. Figure 3 shows hourly-averaged rainfalls obtained from all available PPI scans within that hour, while rainless grids are excluded. For example, at 06 LST, all PPI scans from 05 LST to 06 LST are used for average. Daily rainfall is obtained from accumulation of the hourly values for the rainy grids. The area-averaged rainfall excluding (including) rainless grids at 00, 06, 09, 12, 15, 18, 21 LST and daily rainfall are 10 (2), 22 (3), 6 (1), 7 (0.4), 8 (0.4), 43 (3), 27 (6), and 18 (2.2) $\mathrm{mm}$. Hourly rainfalls of all area are strong from evening (18 LST) to morning (06 LST). At

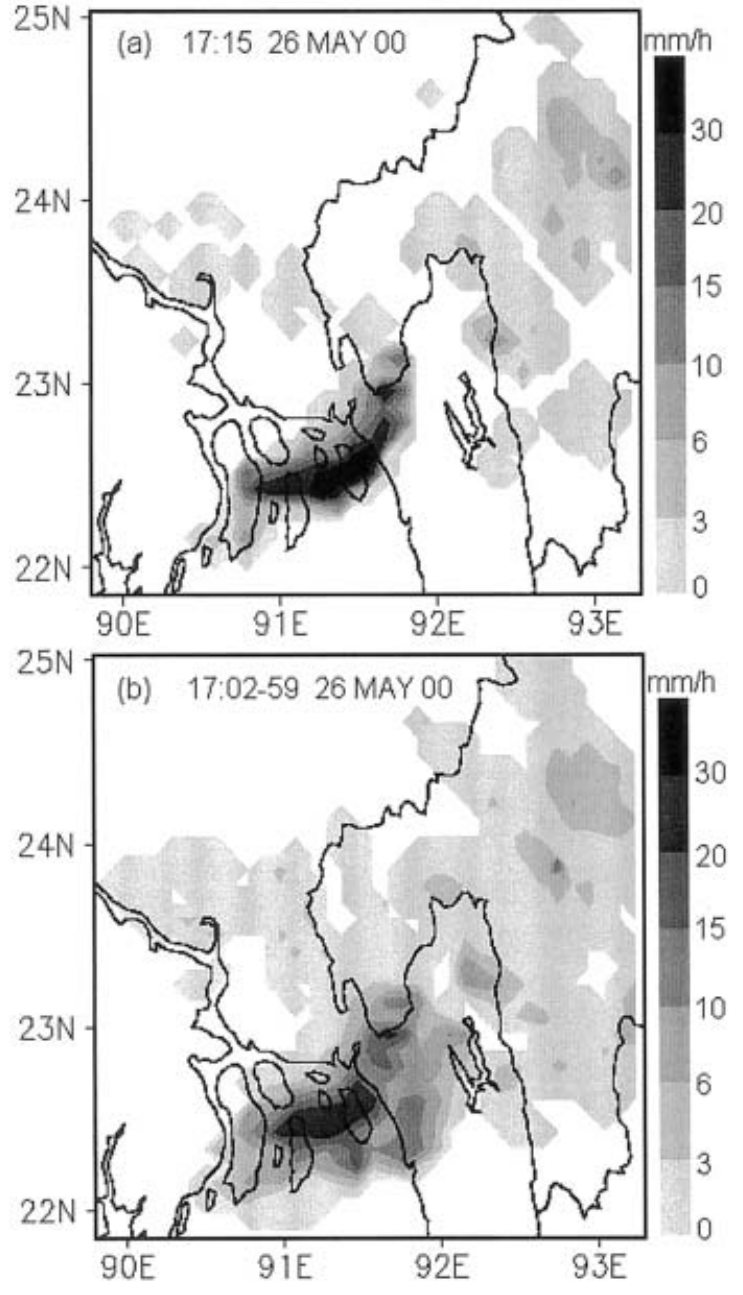

Fig. 2. (a) Instantaneous rain rate $(\mathrm{mm} /$ h) at $1715 \mathrm{LST}$; (b) Spell rain rate (mm/ h) for 1702-1759 LST on 26 May 2000.

$21 \mathrm{LST}$ and $00 \mathrm{LST}$, rainfalls at each grid are not so strong, but rainfall area is larger in this case.

\subsection{Comparing with rain gauge data}

This is the first time to employ the Dhaka radar data for estimation of rainfall over Bangladesh. Therefore, we compare the radar results with rain gauge results.

Figure 4(a) shows daily rainfall estimated by the Dhaka radar at each rain gauge site averaged for 135 days from 16 April to 30 August 2000. The time of maximum daily rainfall at each rain gauge site are also shown using ar- 

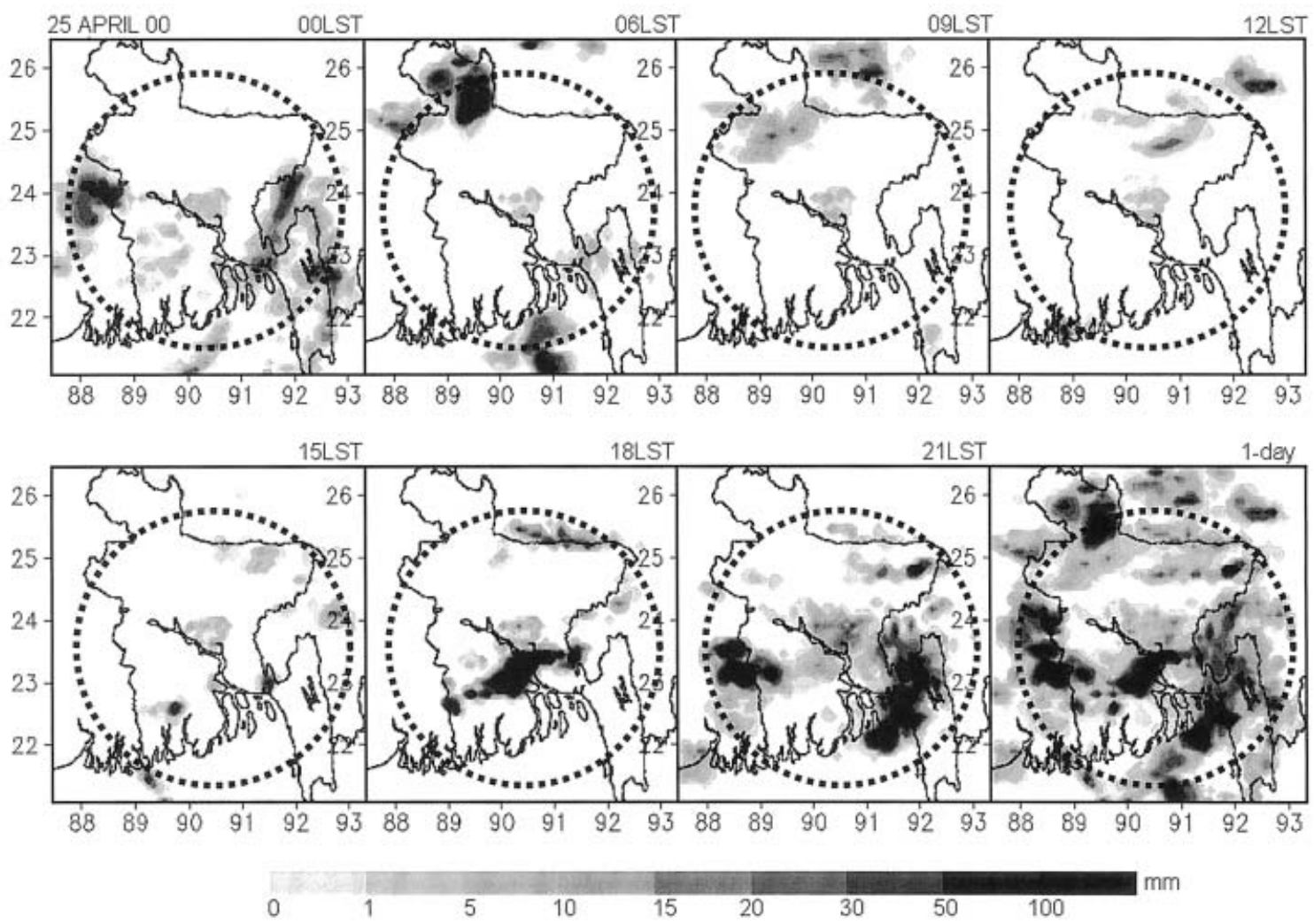

Fig. 3. Hourly and daily rainfall ( $\mathrm{mm}$ ) over Bangladesh on 25 April 2000. Top panel, left to right, for $00,06,09$, and 12; bottom panel, left to right, for $15,18,21$, and 1 day. The hourly values are accumulated for a day in 1 day (no data between 03 and 06 LST). The time is LST (=UTC + 6 hours). Dotted circle denotes the Dhaka radar effect range of observations.

rows. Note that rainless grids are included to obtain hourly as well as daily and monthly rainfall in the rest of the analysis. Figure 4(b) shows daily rainfall estimated from rain gauge data in similar manner of Fig. 4(a).

The quantity of rainfall estimated by the Dhaka radar was much lower than that measured by each rain gauge. The rainfall discrepancy between two may come from inconsistency of temporal and spatial averaging of the radar and the rain gauge data. It may come from rainfall calculation from rain status based on single Z-R relations. This will be discussed in Subsection 4.1. In case of the radar analysis, rainfalls of 16 pixels (each $2.5 \mathrm{~km}$ mesh) in a grid box including rainless pixels are averaged. On the other hand, no spatial average is taken for the rain gauge. As seen in Fig. 4(a), rainfalls estimated by the radar of southeasterly sta- tions show very less than those in Fig. 4(b). This is because these stations are located far from the radar, and out of the effective range of the radar $(250 \mathrm{~km})$. The reduction of the reflectivity is very clear on the out side of the radar's effective radius. The northwest rain gauge stations are located on the rim of the radar's effective range. The rainfall estimated by the radar is consistent with the rain gauge result, with an increasing tendency in the northern stations.

Time of maximum rainfalls obtained by the radar analysis differs remarkably from that obtained by the rain gauges, especially at stations enclosed with dashed lines in Fig. 4(a). Since the Dhaka radar was not operated during 03 LST, we cannot confirm the time of maximum rainfall at the northwest stations. The details are discussed in Subsection 4.2. 

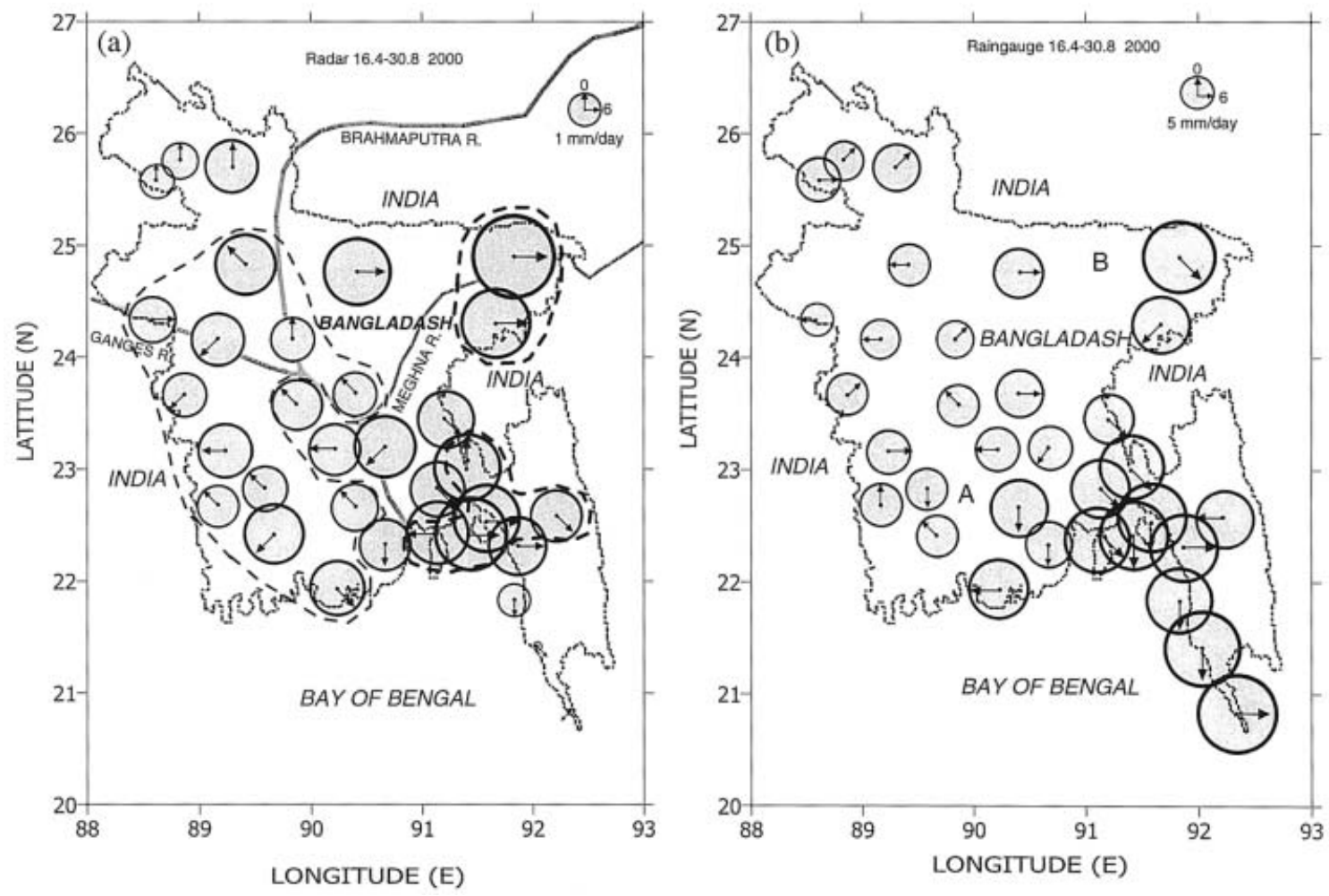

Fig. 4. Daily rainfall averaged for 16 April to 30 August of 2000 in Bangladesh (a) estimated by the Dhaka radar and (b) estimated by rain gauge. The area of the circle is proportional to the volume of daily rainfall. The orientation of arrows indicates the time of maximum rainfall. Arrows pointing to the north, east, south and west denote 00 LST, 06 LST, 12 LST, and 18 LST, respectively. Note that rainfall scale of the rain gauge is 5 times of the radar.

\subsection{Monthly rainfall estimated by the radar}

\section{4.a General features of pre-monsoon and monsoon}

The land-ocean thermal contrast is the primary driver for the Asian monsoon, which is a seasonal scale sea breeze circulation ( $\mathrm{Li}$ and Yanai 1996; Liu and Yanai 2001). In the premonsoon months (April and May), severe premonsoon thunderstorms often appear in Bangladesh. The rainfalls associated with these thunderstorms are characterized by high intensity of the precipitation and short duration. Monsoon rains have different character. They continue long duration over a number of days, and their intensities are not as high as that of pre-monsoon rain. However, there are occasions of cloudbursts within a spell of monsoon rain (Das 1995). Most of the monsoon rainfalls occur in association with synoptic-scale sys- tems, that is, monsoon disturbances, which are generated over the ocean and move to the Indian landmass (Bhat et al. 2001). In particular, the Bay of Bengal is exceptionally fertile of these systems (Rao 1976).

Normal monsoon onset in Bangladesh occurs at 26-30 May in the south and 5-9 June in the middle of the country (Ahmed and Karmakar 1993; Das 1995). Since the objective criteria of the monsoon onset is difficult to decide, subjective decision based on changes in circulation features, seasonal reversal of winds, and a sustained increase in rainfall is used (Pant and Kumar 1997).

\section{4.b Distribution of monthly rainfall}

In order to understand the spatial and temporal characteristics of rainfalls over Bangladesh, monthly averaged rainfalls are calculated from hourly rainfall which is calculated using 

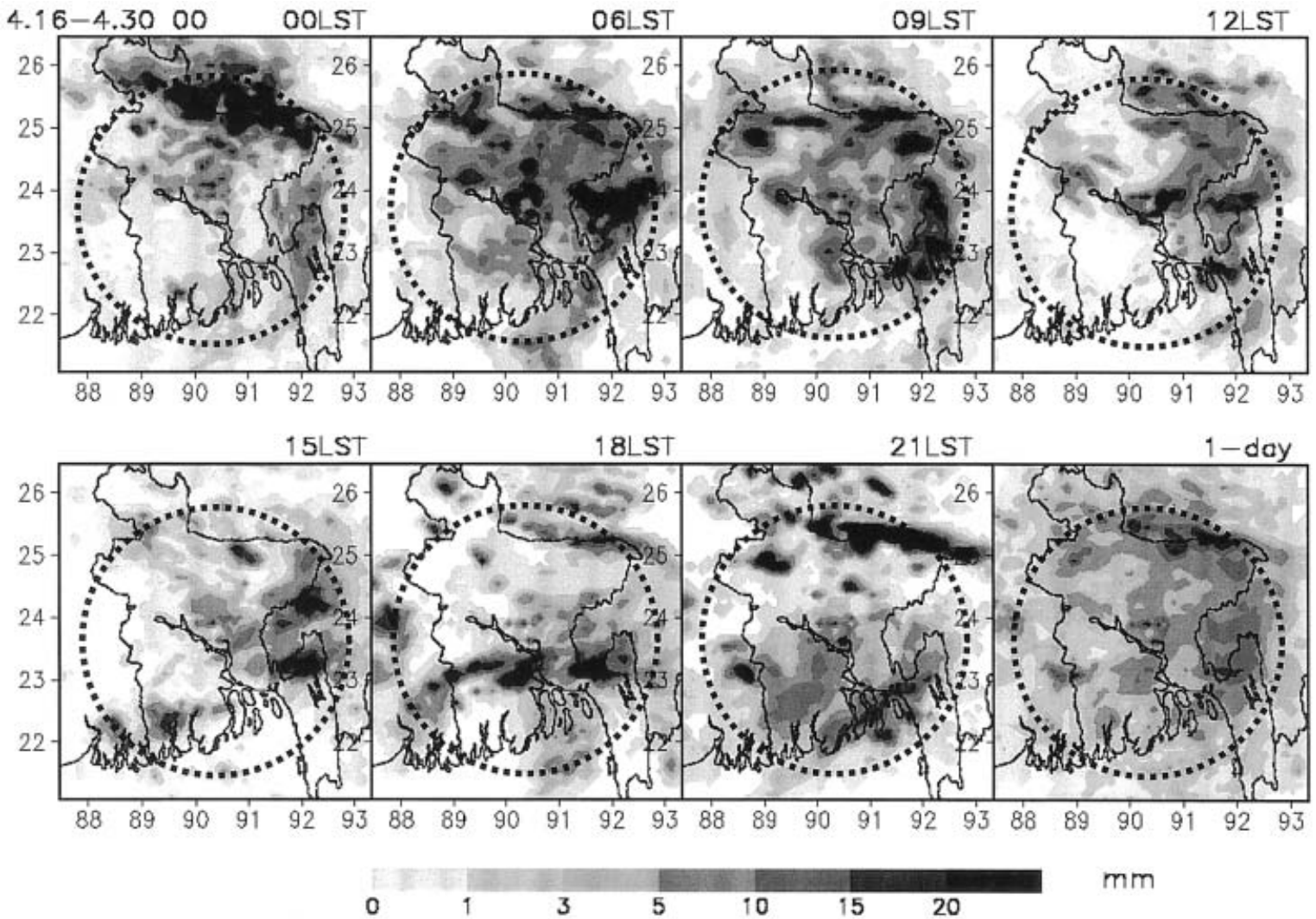

Fig. 5. Temporal and spatial variations of rainfall ( $\mathrm{mm} /$ day) estimated by the Dhaka radar, averaged for 16 to 30 April 2000. One day (1-day) data shows hourly values accumulated for 24 hours.

Eqs. (3) and (4). Monthly averaged diurnal variations from May to August are described elaborately as follows.

a) April 2000 Temporal and spatial variations of rainfall $(\mathrm{mm})$ estimated by the Dhaka radar averaged for 16-30 April 2000 are shown in Fig. 5. In pre-monsoon month, northwesterly winds are predominant in the west-northwest of Bangladesh (see Fig. 13). Thunderstorms which are locally called "Kal-Baisakhi" are sometimes accompanied by tornado and frequently cause considerable damage in this region (Das 1995). These thunderstorms are examples of intensive atmospheric vortices of small dimensions. They are associated with strong convective motion. Heavy rains associated with pre-monsoon thunderstorms are observed in the northern and eastern parts of the country. Heavy rainfalls on the northern border are seen at 21-09 LST, in the east at 0618 LST, and in the central part of the country at $12 \mathrm{LST}$ and $18 \mathrm{LST}$. The northern border has strong rainfall compared to other regions in this month.

b) May 2000 Figure 6 shows the rainfall averaged for 1-30 May 2000. Daily averaged rainfall is the strongest in the north, and the distribution pattern is almost similar to April. May is the last month of the pre-monsoon. Rainfall from 00 to 06 LST is stronger, on average, than that from the rest of the hours throughout the country. Rain on the northern border of the country is remarkably heavy at 00, 06, and 09 LST. Rainfall at 21 LST on the northern border is not so heavy compared with April.

c) June 2000 The monsoon period normally begins at the first week of June in Bangladesh. In 2000, the BMD declared the onset of the monsoon season on 3 June in the southeast coast and on 7 June over other areas of the country. Figure 7 shows the rainfall averaged 

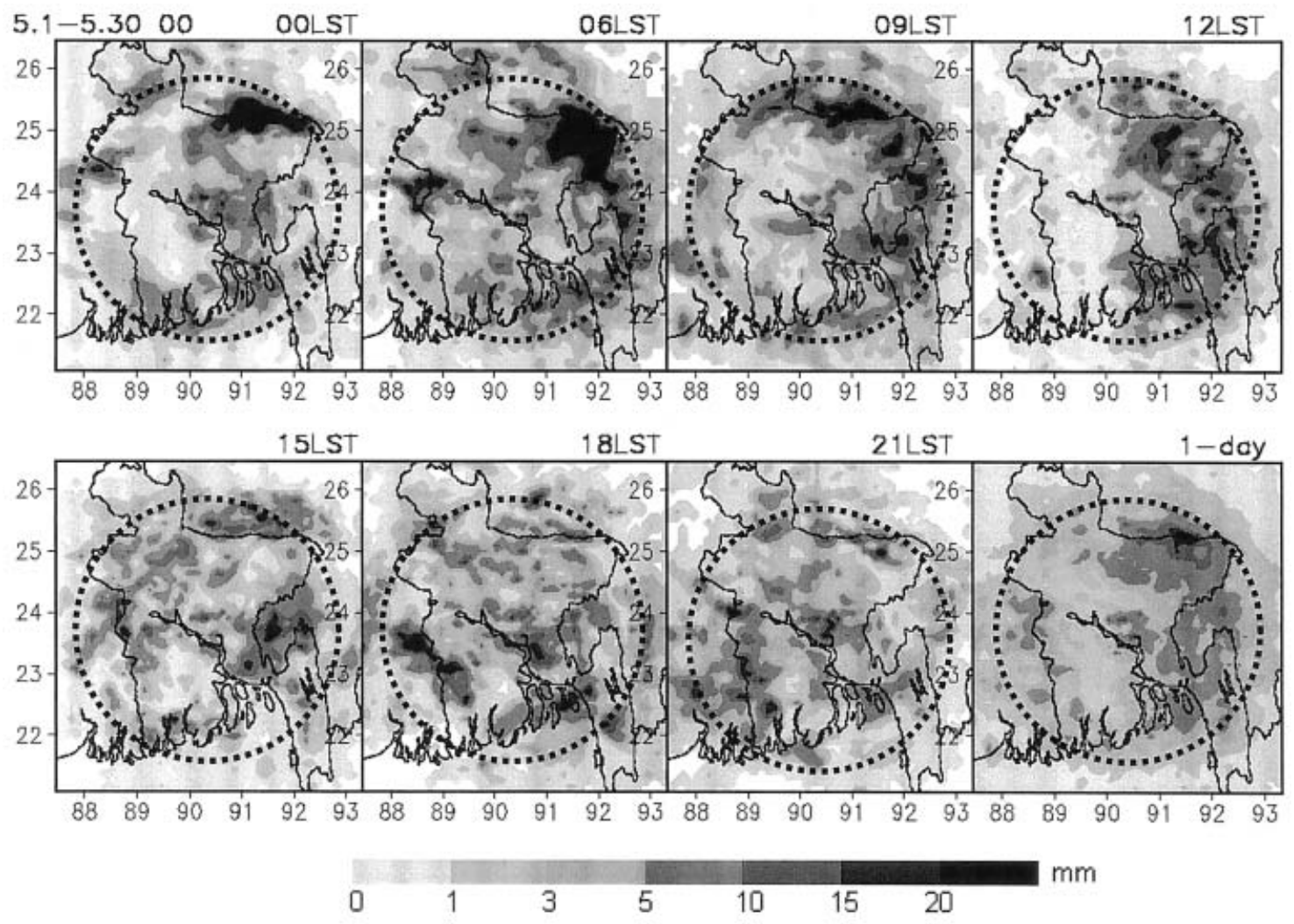

Fig. 6. Same as Fig. 5 but averaged for 1 to 30 May 2000.

for 1-30 June 2000. The northern border has the maximum rain at 00 to $06 \mathrm{LST}$, while the southern costal region has maximum rain during 12 to 18 LST. The western part of the country exhibits strong rainfall from 15 to 21 LST. The daily rainfall is weak in the western part of the country and strong in the north and south.

d) July 2000 The rainfall averaged for 130 July 2000 are shown in Fig. 8. Strong rainfall in the southern coastal region is a characteristic of peak-monsoon months. Rainfall from 21 to 09 LST on the northern border is significantly high. Climatologically, July is the peak monsoon month and it has the most rainfall. However, light rain is dominant throughout the country, although relatively strong rainfall is observed in the north and south of the country. This result is consistent with the rain gauge rainfall seen in the right panel of Fig. 1. Additionally, the monthly-accumulated near-surface rainfall analyzed from TRMM and other satel- lites (3B43 products) also indicates less rain in July (Fig. 10). Peculiarity of rainfall in July 2000 will be discussed later.

e) August 2000 The rainfall averaged for 1-30 August 2000 is shown in Fig. 9. Rainfall from 21 to 06 LST is heavier than the rest of the hours. The distribution of one-day rainfall is similar to that in June except for the strength. The rainfall near the eastern boundary is significantly heavy during 21 to $00 \mathrm{LST}$. This is not seen in other months. The strong morning rain at 06 LST on the northern border and southern coastal region may be linked with the development of convection brought by the geographic effect there.

Figure 10 shows the TRMM 3B43 merged precipitations during peak-monsoon months (June, July and August) in 1999 and 2000. From these figures, it is clearly seen that the rainfalls in July 2000 was deficient over Bangladesh comparing with that of July 1999. 

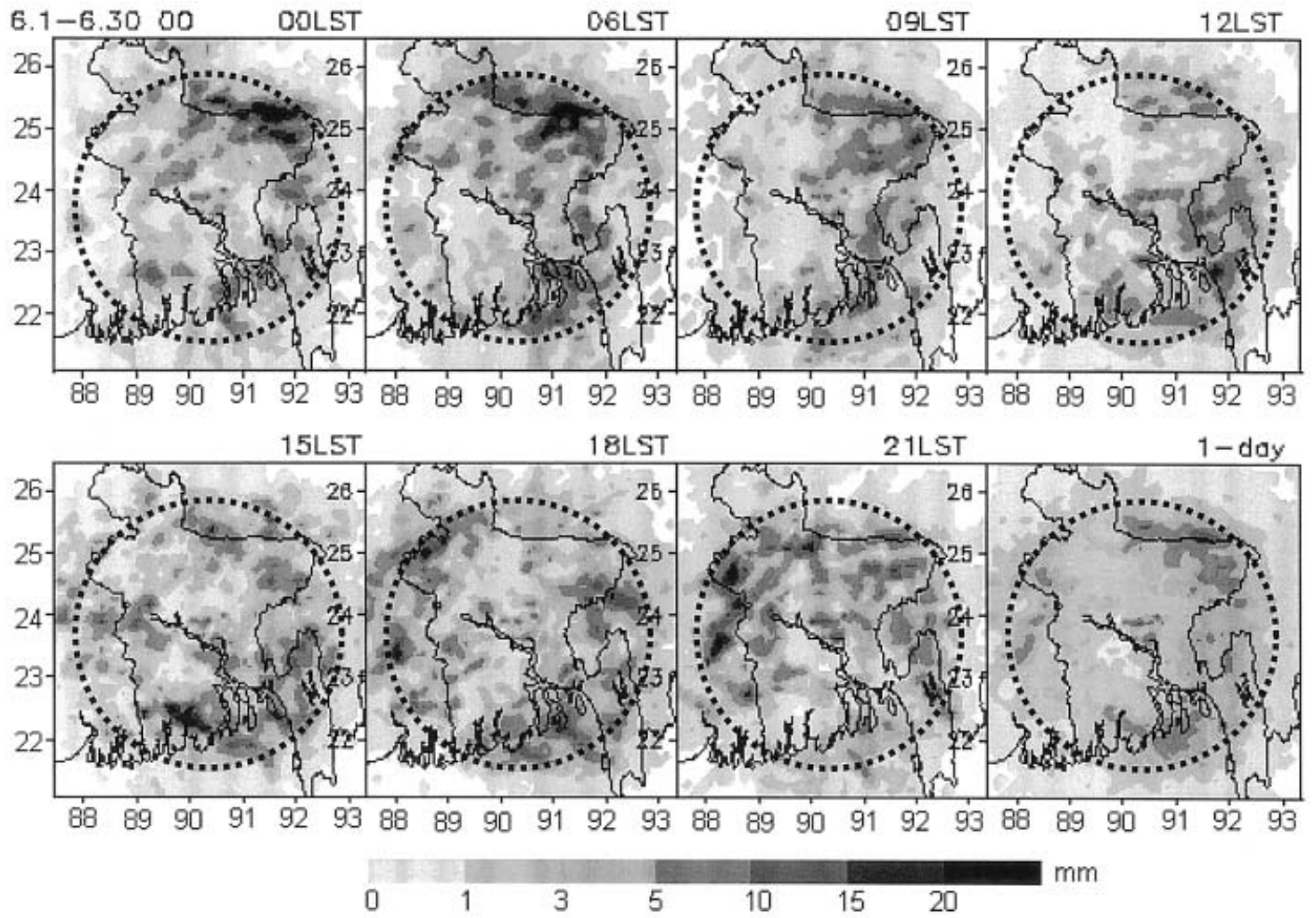

Fig. 7. Same as Fig. 5 but averaged for 1 to 30 June 2000.

\subsection{Seasonal mean rainfall estimated by the radar}

Figure 11 shows the hourly and daily rainfall averaged for 16 April to 30 August 2000 over Bangladesh. Each hourly rainfall shows that strong rain area is seen on the northern border from late night to late morning (21-09 LST). Therefore, for the daily rainfall, the northern and eastern parts of the country had much rain compared to the western and southern parts.

\subsection{Time of maximum rainfall}

Diurnal changes of rain rates of the whole radar regions in each month are presented in Fig. 12(a). Morning peak of rain rates at $06 \mathrm{LST}$ are seen in all months. On the other hand, afternoon peak at 15 LST is also seen in peakmonsoon months (June, July, and August). The appearance of a secondary afternoon peak is consistent with the results of Ohsawa et al. (2001). Figure 12(b) shows diurnal change of rainfalls obtained by the rain gauges data, which is similar to Fig. 12(a). Maximum morn- ing rainfall at 06 LST is obvious in almost all months. The rain rate obtained by the rain gauges in April is lower than the other months, while the rain rate obtained by the radar in April is the highest. It probably comes from strong rains in April fall in the northern border side, where the rain gauge stations are less or none. The rain rate obtained by the rain gauges in July is higher than other months, at least from 03 to 06 LST. This is due to heavy rainfall in the coastal sides in July 2000.

\subsection{Cloud activities in relation to rainfall}

\section{7.a Seasonal change of cloud activity}

The spatial distribution of cloud activity in and around Bangladesh from May to September 2000 is shown in Fig. 13 in order to compare the analysis on the Dhaka radar and see the situation around Bangladesh. Over Bangladesh, intense cloud activity shown by low $T_{B B}$ values is observed from May to August 2000, except in July. The TRMM 3B43 merged 

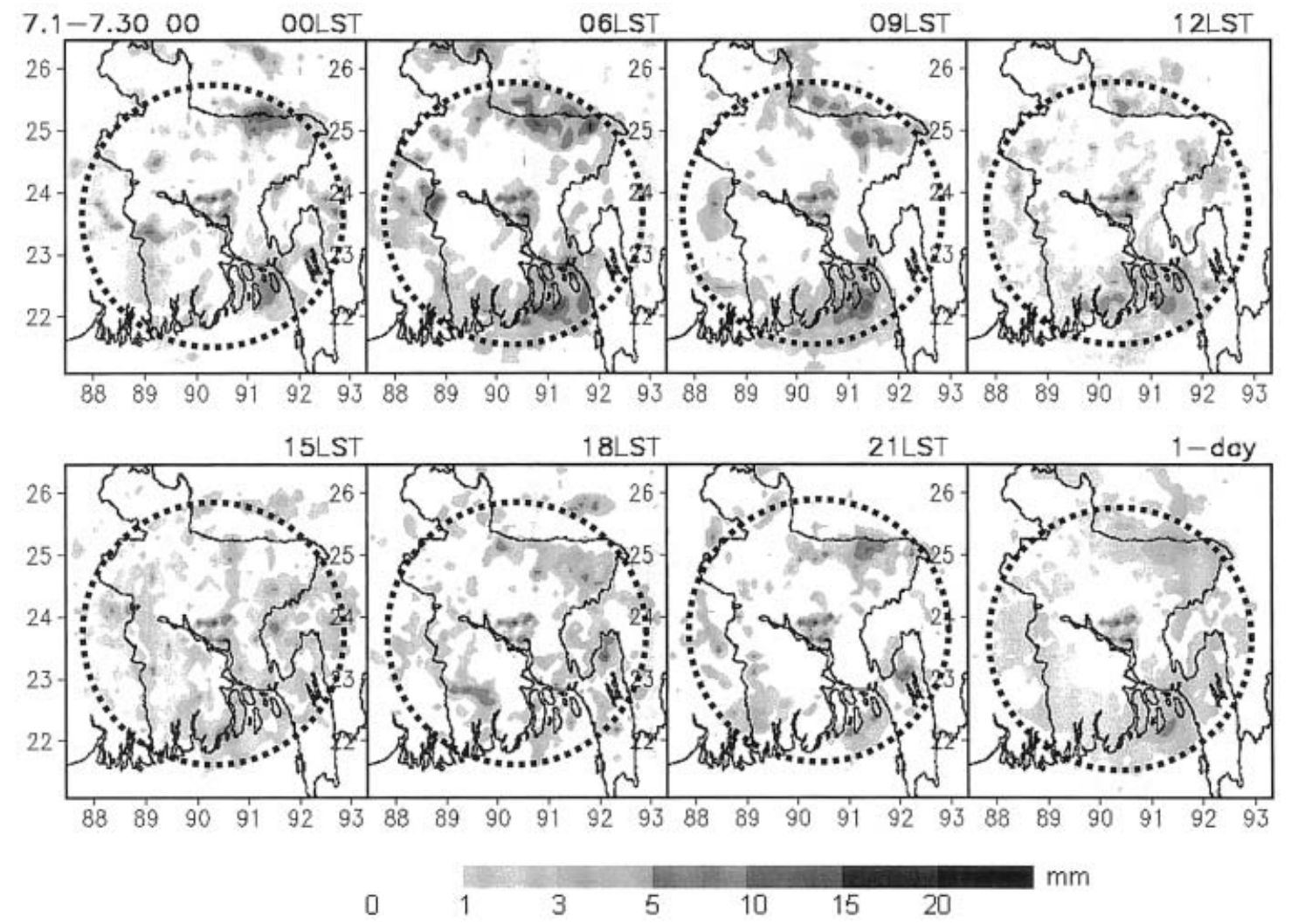

Fig. 8. Same as Fig. 5 but averaged for 1 to 30 July 2000.

analysis also detects less precipitation in July 2000 (Fig. 10). This is consistent with the radar analysis shown in Fig. 8. Over the northern part of the Bay of Bengal, clouds were observed from May to September, especially from June to August. In pre-monsoon months (April and May), strong convective clouds were not observed over Bihar of India, although a few clouds were observed along the Indian coastline. In peak-monsoon months (June, July and August), clouds over Bihar of India and the north-northwestern part of the Bay of Bengal became very active. Clouds over Myanmar were inactive throughout the season. On the other hand, clouds over the south of Nepal and Bhutan were active in both the pre-monsoon and monsoon seasons. In this area, the Himalayas and Tibetan Plateau block the southerly monsoon wind and the Shillong hill blocks the westerly pre-monsoon wind. Additionally, temperature inversion also appears in this area. From NCEP reanalysis data of $850 \mathrm{hPa}$, anti- clockwise wind direction changes with advance of monsoon season were remarkable around Bangladesh (Fig. 13). In pre-monsoon months, southwesterly wind is dominant on the southern side of Bangladesh, and southerly wind is dominant in peak-monsoon months. In September, peak monsoon month end and southerly wind weakens.

\section{7.b Diurnal change of cloud activity}

Figure 14 represents the time of maximum cloud activity in and around Bangladesh. Over the land of Bangladesh, the maximum cloud activity around $21 \mathrm{LST}$ is dominant in pre-monsoon months (AM), while it varies with location during monsoon months (JJAS). In the coastal region of Bangladesh, the maximum cloud activity is almost at 21 LST from April to June and it becomes about 09 LST in July. In August, the maximum cloud activity in the southern side is seen at $06 \mathrm{LST}$ and that in the southeastern side is seen from 18 to 21 LST. 

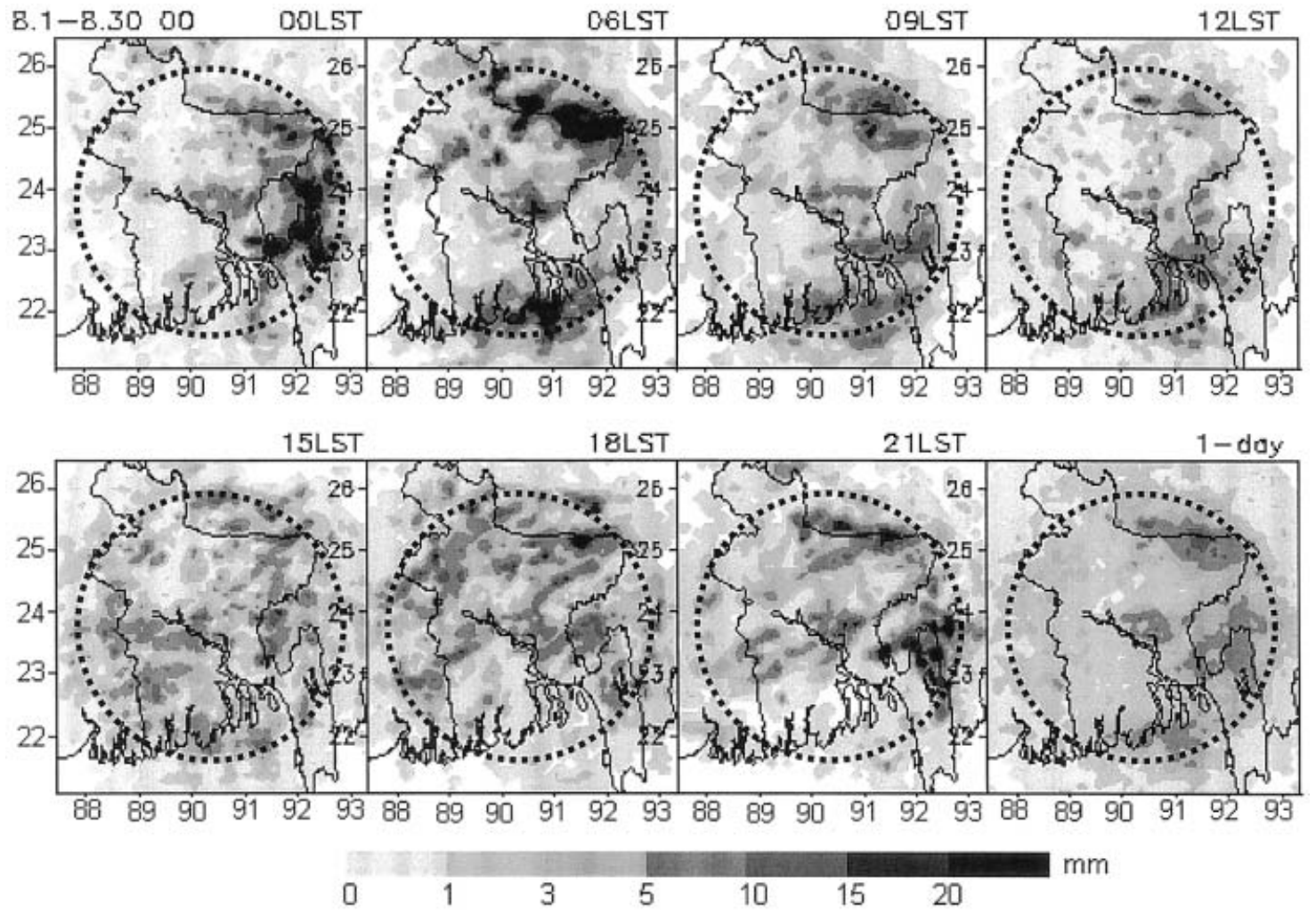

Fig. 9. Same as Fig. 5 but averaged for 1 to 30 August 2000.

Along the Indian coastline, it is at 21 LST in pre-monsoon months (AM), while it becomes at 18 LST during peak-monsoon months (JJA). Over the north of the Bay of Bengal, it is at 09 to 15 LST from June to August.

Another important feature is seen in the rate of cloud development. The rate of cloud development along the Indian coastal region from April to June is much heavier than that in July and August. The rate of cloud development in the Tibetan Plateau shows strong during JulyAugust, and that over West Bengal is strong from June to August. Figure 14 shows seasonal change of cloud activities around Bangladesh along with the time of maximum rainfall in a day.

\section{Discussion}

\subsection{Estimation of rainfall and its distribution over Bangladesh}

As explained in Subsection 3.3, the rainfall estimated by the radar was lower than that estimated by the rain gauges. The standard Z-R relationship (power law: $\mathrm{Z}=200 \mathrm{R}^{1.6}$ ) used in this analysis may contribute to lower rain rate of the radar analysis. Best-fit Z-R relationships for different geographical features are provided by many previous studies (Steiner et al. 1995; Rosenfeld et al. 1995; Ciach et al. 1997). The rainfall estimates vary with the parameters (200 and 1.6) in power law, which are dependent on local climatic conditions (Iguchi et al. 2000). At present, it is difficult to find the bestfit Z-R relationship for Bangladesh using data of one-season.

The spatial distribution of rainfall amount over the country in Fig. 4 is similar to pattern of rainfall in 1995 reported by Ohsawa et al. (2001). Much of the rain comes from the southeastern coastal and northeastern regions. However, the time of maximum rainfall in 2000 somewhat differs from that of 1995 at many stations. The dissimilarity may come from the type of data coverage; radar data are analyzed in $100 \mathrm{~km}^{2}$ coverage, while rain gauges only indicate a point value. The larger area aver- 

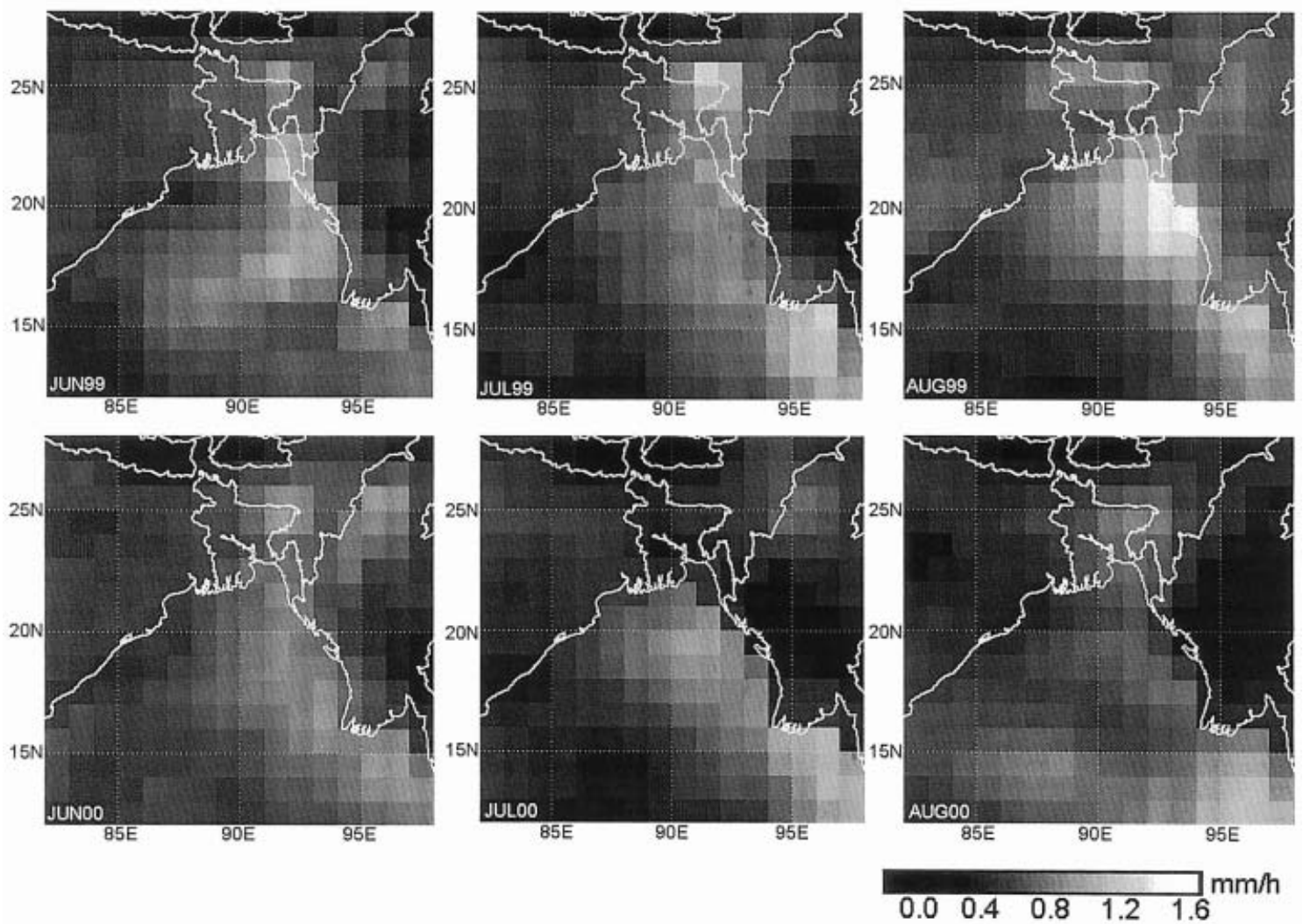

Fig. 10. TRMM merged daily precipitation $(\mathrm{mm} / \mathrm{h})$ for peak-monsoon months (June, July and August) in 1999 and 2000.

aging of the radar may conceal the variation of the time of maximum rainfall measured by the rain gauges in the averaging area. The year-to-year change of diurnal variation of rainfalls in 1995 and 2000 may be another reason.

\subsection{Place and time of maximum rainfall}

In order to check regional monthly rainfall, we divided the total radar data coverage $(600 \mathrm{~km} \times 600 \mathrm{~km})$ into 9 sectors, each having $200 \mathrm{~km} \times 200 \mathrm{~km}$, denoted by C, E, W, N, S, $\mathrm{NE}, \mathrm{SE}, \mathrm{NW}$, and SW, as shown in the inset of Fig. 15. In each sector, the monthly rain rate is averaged over all pixels including rainless pixels. This figure shows that the rain rate in the C, S, E, NE and N sectors are larger for almost all months, and the $\mathrm{N}$ and $\mathrm{E}$ sectors are especially high rain rate regions, as explained in Subsection 3.5. As seen in Fig. 15, the rain rate in July is less than that in other months, while the $\mathrm{S}$ sector shows the maximum rainfalls in this month. It is evident that the rain rate during the pre-monsoon months (AM) is higher than in the peak-monsoon months (JJA). It is one of characteristics of precipitation in this region.

The times of the maximum rainfall in each sector are shown with the vectors in the Fig. 15 inset. The $\mathrm{N}$ and $\mathrm{NE}$ sectors show the maximum rainfall at 00-06 LST, which is caused by influence of the Shillong hill (Prasad 1974; Ohsawa et al. 2001). The evening rainfall at 18 LST in the western sectors reflects the influences of the land characteristics of India. In the $\mathrm{S}$ and SE sectors, rainfalls from 06 to $12 \mathrm{LST}$ are dominative. The coastal region in the $\mathrm{S}$ and $\mathrm{SE}$ sectors includes both land and water area. Contrast between land and water influences the diurnal cycle in the coastal regions. This geographical complexity in the coastal region likely makes differential characteristics of 

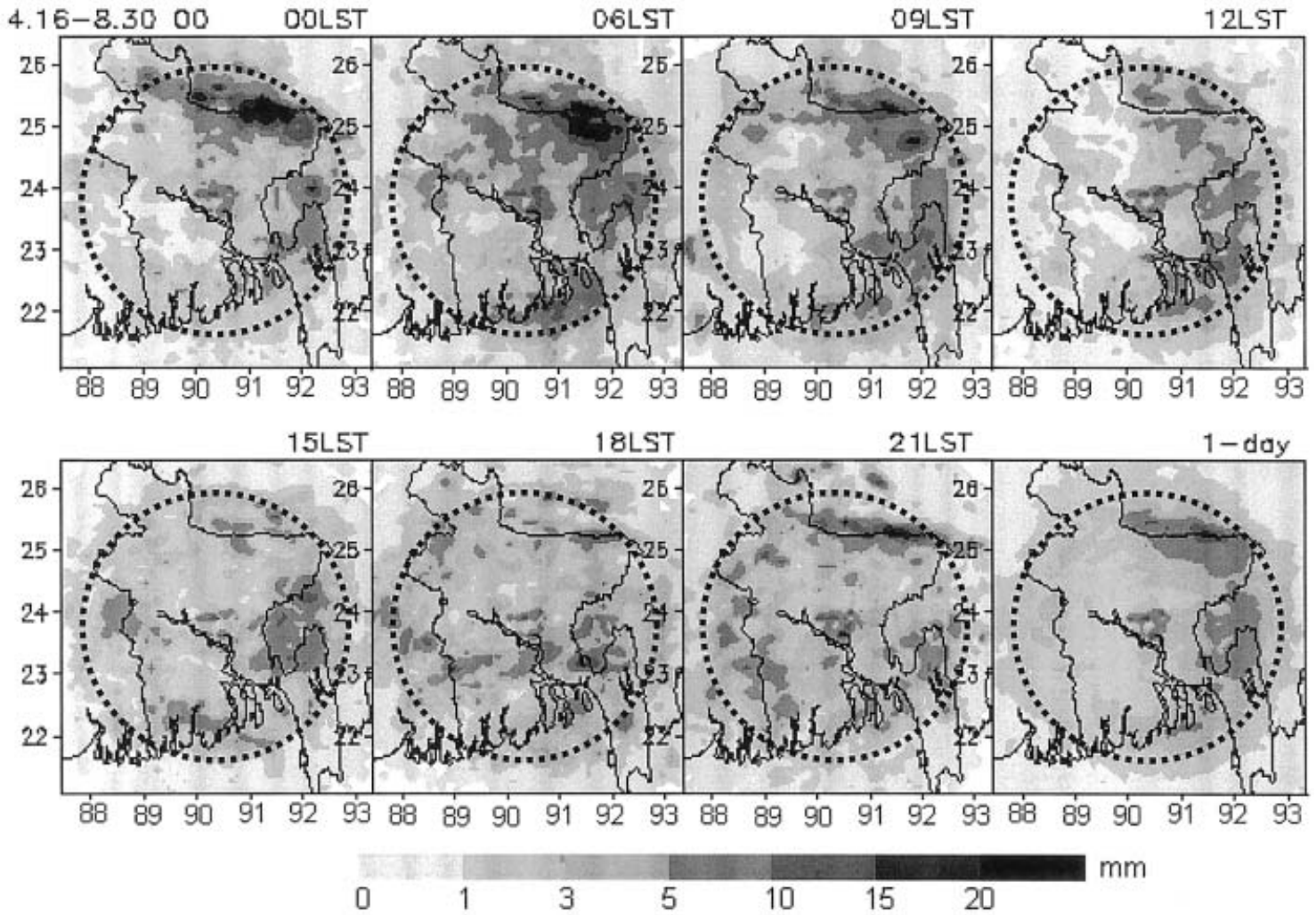

Fig. 11. Same as Fig. 5 but averaged for 16 April to 30 August 2000.

cloud activities over the Bay of Bengal (Zuidema 2003). He showed that the coastal-region rains are brought by small- and medium-sized convections from the Joint Air-Sea Monsoon Interaction Experiment (JASMINE; Webster et al. 2002).

From the rain observations of the TRMM PR, precipitation dominates in the afternoon over land and in the morning over water near coasts (TRMM report 2002). However, eastern areas of Bangladesh show the maximum precipitation in the morning at $06 \mathrm{LST}$, which is different from the Indian Subcontinent and mountain ranges. This difference could be caused by the geographical features of Bangladesh which is flat wetland with many ponds, marshes, and rivers. Additionally, much frequency of rainfall from 21 to 09 LST is observed in the northern, eastern and southern regions (Figs. 5-9 and 15). It is possibly linked to the local effects, such as complex terrain or sea and land breeze circulations.

\subsection{Cloud activities in and around Bangladesh}

Maritime clouds over the ocean are usually shallow cumulus clouds that produce warm rain, while continental tall clouds produce cold rain (TRMM report 2002). However, as seen in Fig. 13, the mean $T_{B B}$ of $<225 \mathrm{~K}$ regions is observed on the ocean as well as over the land. It is also seen in the TRMM PR observation. Monthly mean storm height in July 2000 is reported about 4-7 km over the land of Bangladesh and about 5-8 km over the Bay of Bengal. Moreover, TRMM observations showed a strong rain rate $(>20 \mathrm{~mm} /$ day $)$ on the northeast rim of the Bay of Bengal along Bangladesh and Myanmar coastlines. Vertical structure of maritime cloud using the ground based radar is needed to clarify the situation like this. Unfortunately, Dhaka radar is now operated with limited PPI scans. Further studies using more appropriate observational data will be necessary. 

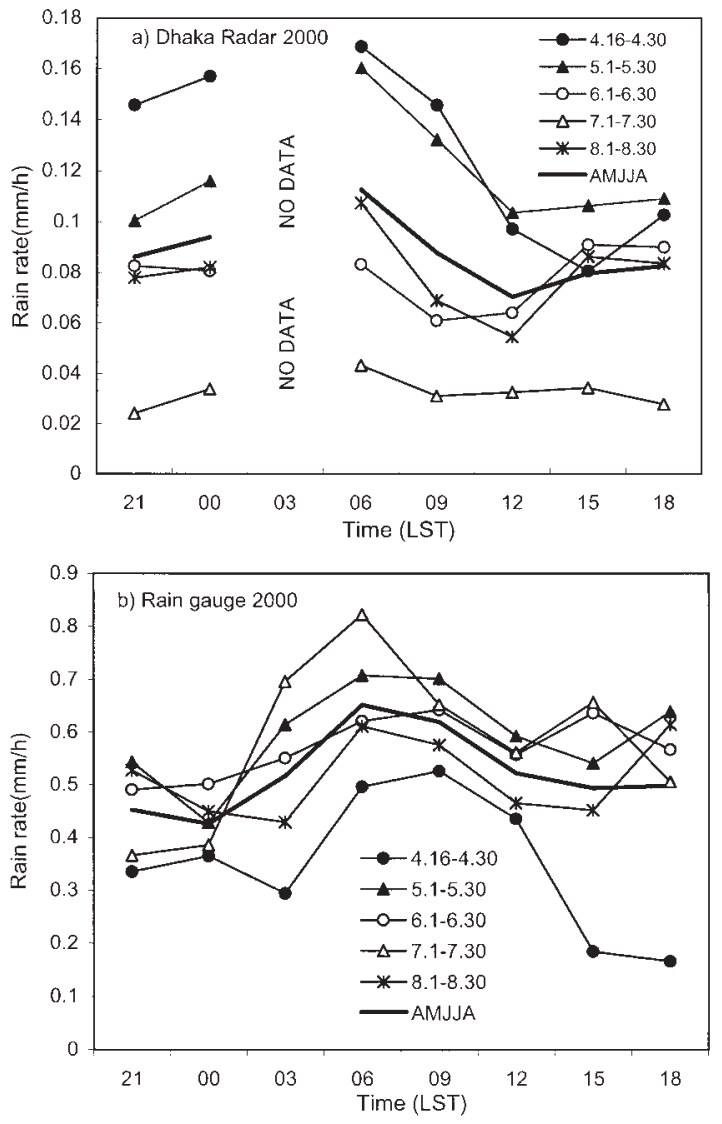

Fig. 12. Rain rate $(\mathrm{mm} / \mathrm{h})$ determined by (a) Dhaka radar and (b) Rain gauge at different hours in different months of 2000 .

A part of heavy rain around Bangladesh is caused by the transportation of moist air from the south and its lifting over the north slope of the Himalayas and the Tibetan Plateau. Ohsawa et al. (2001) and Prasad (1974) proposed the possibility of another mechanism. Amount of rainfall depends on the moisture content of the air and its ascent rate. The ascent rate is controlled by the low-level convergence, which is reflected by local orographic features (Prasad 1974). There are many plateaus and hills in the north and east of Bangladesh. It is likely that those plateaus and hills cause convergence of the southwesterly wind over the north and east of Bangladesh and intensify local convective activity (Ohsawa et al. 2000). The local orographic effect to the monsoon rainfall in Ban- gladesh should be examined in more detail using radar observation.

\section{Conclusions}

Preliminary results of spatial and temporal variations of precipitation in Bangladesh are presented in this paper using the Dhaka radar data from 16 April to 30 August 2000, which is the first research work in Bangladesh. Rainfall data were obtained from the radar information using $10 \mathrm{~km}$ grid boxes inside of the radar domain of $600 \mathrm{~km}$ by $600 \mathrm{~km}$. The instantaneous and spell rain rate, hourly, monthly, and seasonal rainfall obtained by the radar helped us to understand the detailed distribution of precipitation in this region. The distribution of rainfall obtained by the radar is checked by comparison with that obtained by rain gauge network over the country. The rain distribution obtained by the radar and the rain gauges were similar, while the time of maximum rainfall determined by the radar slightly differed from that determined by the rain gauges. The amount of rainfall determined by the radar was lower than that of the rain gauges. The data coverage of the two may be responsible for the dissimilarities: rainfalls estimated by the radar are averaged over $100 \mathrm{~km}^{2}$, while the rain gauges provide only point value. The range limitation of the Dhaka radar is also a candidate for the dissimilarities of rainfall amount.

Using the radar data, it was revealed that the peak time of rainfall averaged over Bangladesh is at 06 LST for AMJJA, while different sectors have different local times. The morning maximum rainfall at 06 LST of Bangladesh is very different from the usual characteristics generally observed on land, which may be due to the wetness and oceanic character of Bangladesh. In Bangladesh, the heavy rainfall areas are northern, eastern, and southern regions, and the northern border is the heaviest. The pre-monsoon rain rate is higher than the peak-monsoon rain rate that reveals the basic properties of precipitation in Bangladesh, that is, pre-monsoon thunderstorms are very strong.

The GMS-5 data analysis in a large domain helped us to understand the cloud activity in relation to rainfall in Bangladesh from pre-monsoon to monsoon seasons. It revealed that cloud activity over Bangladesh was active through May to August 2000 except in July, 


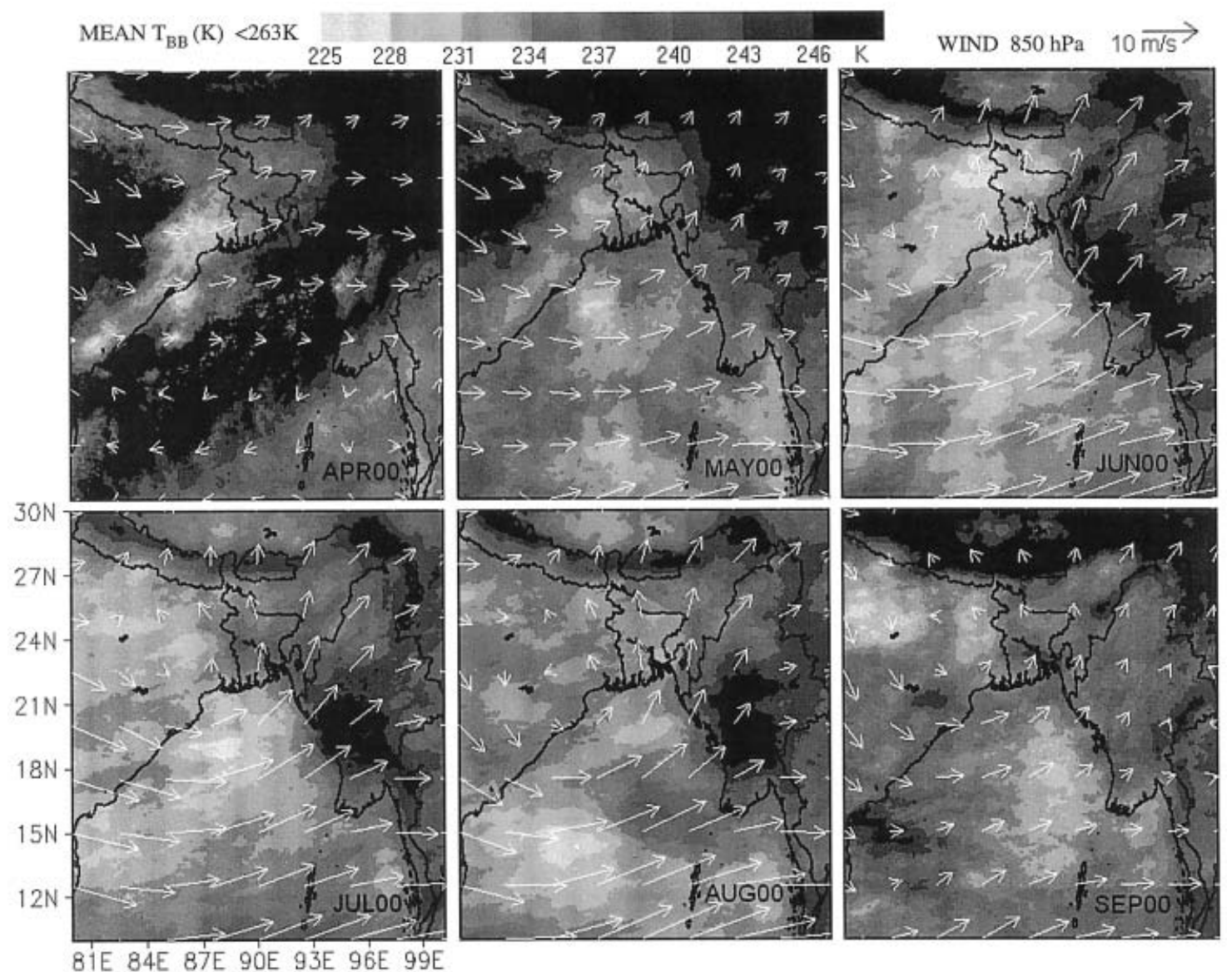

Fig. 13. Spatial distribution of cloud activity in and around Bangladesh calculated using hourly $T_{B B}$ data from GMS-5. The monthly data with a resolution of $0.1^{\circ}$ are averaged in $1^{\circ}$ grid box. Shades show $T_{B B}$ regions of $225-228 \mathrm{~K}, 228-231 \mathrm{~K}, \ldots,>246 \mathrm{~K}$. The arrows represent the monthly mean wind at $850 \mathrm{hPa}$ based on the NCEP reanalysis data.

which supports the rainfall data obtained by the radar. In July 2000, most of the rainfall comes from the coastal regions that demonstrate maximum daily rainfall during 03 to 06 LST (Fig. 12(b)).

This work reveals that the high-resolution radar data provides the proper determination of spatial and temporal variations of precipitation over Bangladesh. It encourages further studies using long-term radar data.

\section{Acknowledgements}

The authors would like to thank the BMD for providing radar and rain gauge data collected under the JICA "Japan Bangladesh Joint Study Project-Phase II" under grant No. 11691151. One of the authors, Nazrul Islam, was fully supported during the course of this study by the Islamic Development Bank (IDB) of Saudi Arabia under the IDB merit scholarship program. Dr. Jun Matsumoto, University of Tokyo, is gratefully acknowledged for his assistance with copying radar data. Thanks are also given to Takeshi Maesaka and Kohei Sakamoto of Nagoya University for their invaluable help with data processing. The GMS-5 data were provided by the Japan Meteorological Agency from HyARC, Nagoya University, Japan. The data used in Fig. 10 was acquired as part of the Tropical Rainfall Measuring Mission (TRMM). The algorithms were developed by the TRMM Science Team. The data were processed by the TRMM Science Data and Information System (TSDIS) and TRMM office; they are archived 


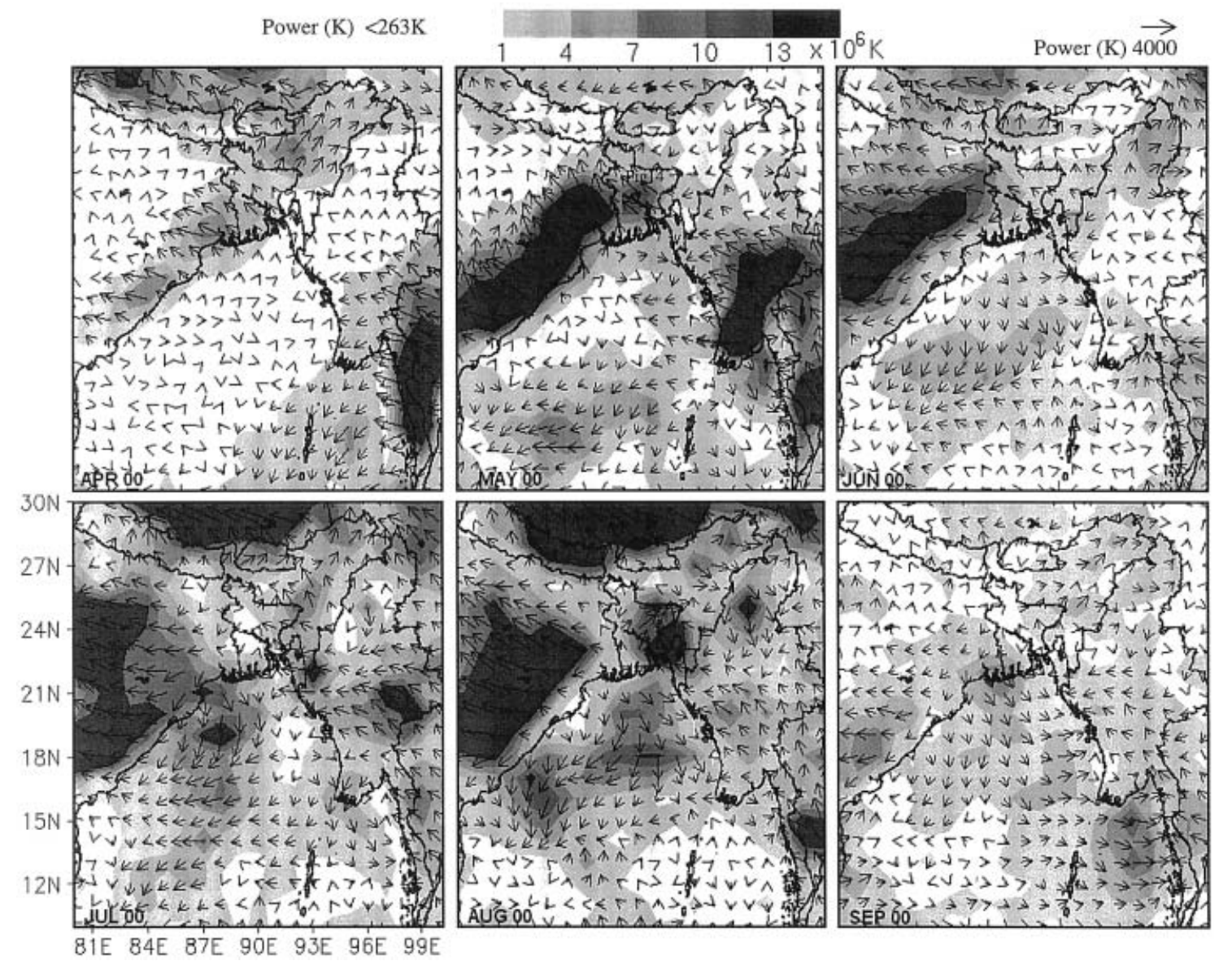

Fig. 14. The rate of cloud development and time of maximum cloud activity in and around Bangladesh. The arrows represent the time of maximum activity. Their orientations indicate the time of maximum cloud occurrence in LST (= UTC +6 hours). The shades represent the rate of cloud development at each location.

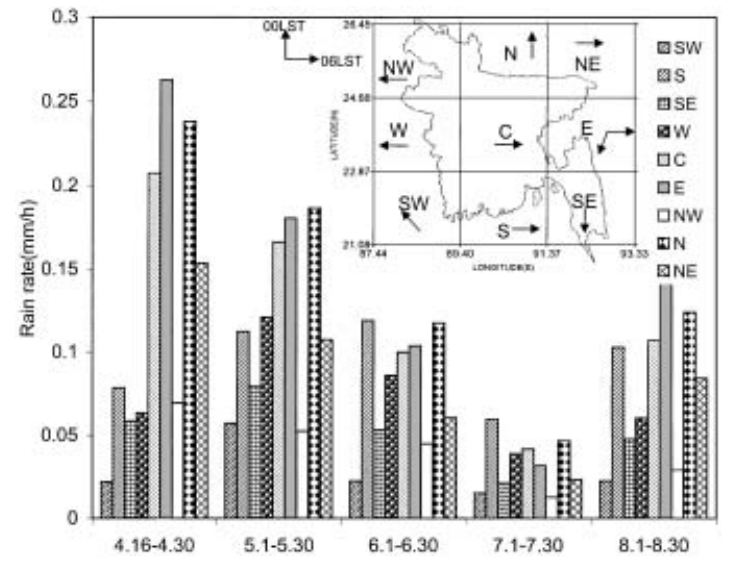

Fig. 15. Rain rate $(\mathrm{mm} / \mathrm{h})$ estimated by radar for different months in 2000 in different sectors (inset). The arrows represent the time of maximum rainfall in each sector of whole analysis period (16 April-30 August 2000). 
and distributed by the Goddard Distributed Active Archive Center. TRMM is an international project jointly sponsored by the Japan National Space Development Agency (NASDA) and U.S. National Aeronautics Space Administration (NASA) Office of Earth Science. The NCEP reanalysis data were provided by NOAA from its website at http://www.cdc.noaa.gov. The constructive criticisms of two anonymous reviewers and the Editor of JMSJ greatly improved this manuscript. This study is partly supported by TRMM-RA4 of the Japan Aerospace Exploration Agency (JAXA).

\section{References}

Ahmed, R. and S. Karmakar, 1993: Arrival and withdrawal dates of summer monsoon in Bangladesh. Intl. J. Climatol., 13, 727-740.

Anagnostou, E.N. and W.F. Karajewski, 1999: Realtime radar rainfall estimation. Part II: Case study. J. Atmos. Oceanic Technol., 16, 198-205.

Bhat, G.S., S. Gadgil, P.V. Hareesh Kumar, S.R. Kalsi, P. Madhusoodanan, V.S.N. Murty, C.V.K. Prasada Rao, V. Ramesh Babu, L.V.G. Rao, R.R. Rao, M. Ravichandran, K.G. Reddy, P. Sanjeeva Rao, D. Sengupta, D.R. Sikka, J. Swain, and P.N. Vinayachandran, 2001: BOBMEX, the Bay of Bengal Monsoon Experiment. Bull. Amer. Meteor. Soc., 82(1), 2217-2243.

Ciach, G.J., W.F. Krajewski, E.N. Anagnostou, M.L. Baeck, J.A. Smith, J.R. McColum, and A. Kruger, 1997: Radar rainfall estimation for ground validation studies of the tropical rainfall measuring mission. J. Appl. Meteor., 36, $736-747$.

Das, P.K., 1995: The Monsoons, Third Edition, published by the Director, National Book Trust, New Delhi, India.

Hamada, J.-I., M.D. Yamanaka, J. Matsumoto, S. Fukao, P.A. Winarso, and T. Sribimawati, 2002: Spatial and temporal variations of the rainy season over Indonesia and their link to ENSO. J. Meteor. Soc. Japan, 80(2), 285-310.

Houze, R.A. Jr., 1993: Cloud Dynamics. Academic Press, Inc. New York. 341-348.

Iguchi, T., R. Meneghini, J. Awaka, T. Kozu, and K. Okamoto, 2000: Rain profiling algorithm for TRMM precipitation radar data. Adv. Space Res., 25(5), 973-976.

Islam, M.N., H. Uyeda, O. Kikuchi, and K. Kikuchi, 1998: Convective and Stratiform Components of Tropical Cloud Clusters in Determining Radar Adjusted Satellite Rainfall during the TOGACOARE IOP. J. Fac. Sci, Hokkaido Univ. Japan, Ser. Vll (Geophysics), 11(1), 265-300.
T. Terao, T. Hayashi, J. Matsumoto, and T. Oka, 2001: Estimation of monsoon rain and the use of BMD radar data. Proceedings of the $3^{\text {rd }}$ International Symposium on Asian Monsoon (ISAM3), Okinawa, Japan, December 2001, 298-303. , T. Hayashi, T. Terao, J. Matsumoto, K. Kikuchi, and H. Uyeda, 2002: Rainwater from the Tropical Mesoscale Convective Systems-A Case Study. Proceedings in the Int. Conf. On the Mesoscale Convective System and Heave Rainfall/Snowfall in East Asia, 29-31 Oct., Tokyo, Japan, 71-76.

,,-- H. Uyeda, T. Terao, and K. Kikuchi, 2004: Diurnal variations of cloud activity in Bangladesh and north of the Bay of Bengal in 2000. Remote Sensing of Environment, 90(3), 378-388.

Karmaker, S. and A. Khatun, 1995: Variability and probabilistic estimates of rainfall extremes in Bangladesh during the southwest monsoon season. MAUSAM, 46, 47-56.

Kummerow, C., J. Simpson, O. Thiele, W. Barnes, A.T.C. Chang, E. Stocker, R.F. Adler, A. Hou, R. Kakar, F. Wentz, P. Ashcroft, T. Kozu, Y. Hong, K. Okamoto, T. Iguchi, H. Kuroiwa, E. Im, Z. Haddad, G. Huffman, B. Ferrier, W.S. Olson, E. Zipser, E.A. Smith, T.T. Wilheit, G. North, T. Krishnamurti, and K. Nakamura, 2000: The Status of the Tropical Rainfall Measuring Mission (TRMM) after Two Years in Orbit. J. Appl. Meteor., 39, 1965-1982.

Li, C. and M. Yanai, 1996: The onset and international variability of the Asian summer monsoon in relation to land-sea thermal contrast. J. Climate, 9, 358-375.

Liu, X. and M. Yanai, 2001: Relationship between the Indian monsoon rainfall and the tropospheric temperature over the Eurasian continent. Quart. J. Roy. Meteor. Soc., 127, 909937.

Matsumoto, J., 1988: Synoptic features of heavy monsoon rainfall in 1987 related to the severe flood in Bangladesh. Bulletin of the Dept. Geography, Univ. Tokyo, Japan, 20, 43-56.

-, M.R. Rahman, T. Hayashi, and N. Monji, 1996: Rainfall distribution over the Indian Subcontinent during the 1987 and 1988 severe floods in Bangladesh. Bulletin of the Dept. Geography, Univ. Tokyo, Japan, 28, 25-44.

Ohsawa, T., T. Hayashi, and Y. Mitsuta, 2000: Interseasonal variation of monsoon activities associated with the rainfall over Bangladesh during the 1995 summer monsoon season. J. Geophys., Res., 105, D24: 29445-29459.

, H. Ueda, T. Hayashi, A. Watanabe, and J. 
Matsumoto, 2001: Diurnal variations of convective activity and rainfall in tropical Asia. $J$. Meteor. Soc. Japan, 79, 333-352.

Pant, G.B. and K.R. Kumar, 1997: Climates of South Asia. Wiley publications.

Prasad, B., 1974: Diurnal variation of rainfall in Brahmaputra valley. Ind. J. Met. Geophysics, 25(2), 245-250.

Rao, Y.P., 1976: Southwest monsoon, Synoptic Meteorology, Meteorological Monogr., India Meteorological Department, 1, 367.

Rosenfeld, D., E. Amitai, and D.B. Wolff, 1995: Improved accuracy of radar WPMM estimated rainfall upon application of objective classification criteria. J. Appl. Meteor., 34, 212-223.

Steiner, M. and R.A. Houze, Jr., 1995: Sensitivity of the estimated monthly convective rain fraction to the choice of Z-R relation. J. Appl. Meteor., 36, 452-462.

TRMM report, 2002: Rain as seen from space, Edited by "Rain as seen from space" production committee, published by Japan Advanced Plan Co.,
Inc. First edition, 31 May 2002.

Wahid, C.M., R. Rahman, and M.N. Islam, 1999: Single cell and multiple cell clouds analyzed with satellite data in and around Bangladesh. MAUSAM, 50(2), 177-180.

— and M.N. Islam, 1999: Patterns of rainfall in the northern part of Bangladesh. Bang. J. Sci. Res., 17(1), 115-120.

Webster, P.J. and R. Lukas, 1992: TOGA COARE: The Coupled Ocean-Atmosphere Response Experiment. Bull. Amer. Meteor. Soc., 73, 13771416.

Webster, P. and coauthors, 2002: The JASMINE pilot study. Bull. Amer. Meteor. Soc., 83, 16031630.

Weller, R.A. and S.P. Anderson, 1996: Surface meteorology and air-sea fluxes in the western equatorial Pacific warm pool during the Coupled Ocean-Atmosphere Response Experiment. $J$. Climate, 9, 1959-1990.

Zuidema, P., 2003: Convective clouds over the Bay of Bengal. Mon. Wea. Rev., 131, 780-798. 